\title{
The Effect of Different Orthodontic Forces on MMP 9 Expression in a Rat Diabetic Model
}

\author{
Hafiedz Maulana ${ }^{*}$, Nuzulul Hikmah ${ }^{1}$, Amandia Dewi Permana Shita ${ }^{1}$, \\ Nur Permatasari ${ }^{2}$, and Sri Widyarti ${ }^{3}$ \\ ${ }^{1}$ Master Program of Biomedic Science, Medical Faculty, Brawijaya University, Malang - Indonesia \\ ${ }^{2}$ Laboratory of Pharmacology, Medical Faculty, Brawijaya University, Malang - Indonesia \\ ${ }^{3}$ Biology Department, Mathematics and Natural Sciences Faculty, Brawijaya University, \\ Malang - Indonesia
}

\begin{abstract}
Orthodontic forces produce alveolar bone and periodontal ligament remodeling that cause tooth movement. Diabetes can increase tissue damage and, therefore, contributes to the process of orthodontic tooth movement. The aim of this study was to determine the effect of differently orthodontic forces on the expression of MMP nine in rat diabetic model. Twenty four male Wistar rats were divided into three groups of control and three groups of treatment streptozotocin-induced diabetes with stratified doses. Application of orthodontic appliance was performed with different forces $(10,20$ and $30 \mathrm{grF})$. Orthodontic appliance was performed on both upper incisors. Immunohistochemical (IHC) analysis was used to observe the expression of MMP 9 and HE (Hematoxylen Eosin) staining to observe the number of fibroblasts. Statistical analysis was carried out using t-test and Spearman correlation analysis to determine the difference of MMP nine expression and number of fibroblasts between groups, and determine the correlation of both. The results showed an increased expression of MMP 9 and decreased of fibroblasts number in diabetic rats, along with increasing magnitude of orthodontic forces. The different orthodontic forces given to diabetic rats affect the expression of MMP 9 and the number of fibroblasts, in which the expression of MMP 9 increased along with the increase of orthodontic forces, both at pressure and tension sides..
\end{abstract}

Keywords: Orthodontic force, diabetes, MMP 9, fibroblast, remodeling

\section{INTRODUCTION}

Application of orthodontic force causes the formation of stress and tension side on the periodontal ligament [1]. Alveolar bone resorption on the pressure side is played by osteoclasts and opposition of alveolar bone in the tension side is played by osteoblasts [2, 3].

MMPs (matrix metalloproteinases) are a large family of proteo-lytic enzymes $\mathrm{Zn}^{2+}$-dependent which is responsible to the degradation of the extracellular matrix. MMP nine is included in the

"Corresponding author:

Hafiedz Maulana

Master Program of Biomedic Science, Medical Faculty,

Brawijaya University, Jl. Veteran Malang - Indonesia 65145

E-mail: hafiedz.drg@gmail.com class of gelatinase (gelatinase B, 92-kDa type IV collagenase) that is expressed as a pro-enzyme, and can be activated to be enzyme. The main substrate of gelatinases is denatured collagen [4] and collagen fragments generated by collagenases in bone. MMP 9 activity is associated with the inflammatory process [5] and expressed in periodontal tissues on orthodontic tooth movement [6].

Diabetes mellitus is a metabolic disease characterized by high blood glucose levels (hyperglycemia) due to disturbances in insulin secretion, insulin action, or both. Diabetes can increase periodontal tissue damage [7]. In diabetes condition, there is an increased production of AGEs (advanced glycation end products), ROS (reactive oxygen species) and TNF, which affects the development of periodontal disease [8]. 
Metabolic changes (such as diabetes) can interfere with bone remodeling that can lead to differences in the rate of tooth movement $[9,10]$. Diabetes affects osteoblasts, fibroblasts, and collagen expression, through the process of inflammation and apoptosis [8]. Diabetes is also believed to affect the expression of MMP nine in the process of periodontal tissue remodeling in orthodontic tooth movement.

The aim of this study was to determine the effect of different orthodontic force application in a rat diabetic model on the expression of MMP 9, the number of fibroblasts, as well as the relationship between the expressions of MMP 9 with the number of fibroblasts.

\section{MATERIALS AND METHODS}

\section{Experimental Animals}

Twenty-four, four-month-old male Wistar rats (Rattus norvegicus) with an average body weight 250-300 g, healthy and had no abnormalities were used in this study. Experimental animals were divided into six groups (consisting four rats in each group). The division of groups consists of, K1 (normal, without orthodontic appliances), K2 (diabetes, without orthodontic appliances), K3 (normal, with orthodontic appliance $30 \mathrm{grF}$ ), K4 (diabetes, with orthodontic appliance $10 \mathrm{grF}$ ), K5 (diabetes, with orthodontic appliance $20 \mathrm{grF}$ ), and K6 (diabetes, with orthodontic appliance 30 grF). All study procedures were conducted in accordance with the guidelines approved by the Ethics Committee of the Medical Faculty of Brawijaya University, Malang, East Java, Indonesia.

\section{Induction of Streptozotocin Stratified Dose (STZ-SD) on Experimental Animals}

Before the induction, the experimental animals were acclimatized for seven days, and then fasted for eight hours. Induction of Streptozotocin (code 32238-91, Nacalai Tesque Inc., Kyoto, Japan) was performed using stratified doses $(40,35,30,25$, and $20 \mathrm{mg} / \mathrm{kgBB})$ for five consecutive days in the morning through intraperitoneal. Furthermore, experimental animals were incubated for seven days, and observed for the blood glucose levels taken from the tail vein using a digital glucometer (Nesco,
Japan). Rats with diabetes are characterized by Blood Glucose $>300 \mathrm{mg} / \mathrm{dl}$ [11].

\section{Orthodontic Appliances}

Orthodontic appliance design used in this study is a modification of some previous studies $[12,13]$. Design and magnitude of orthodontic force was confirmed with tool ANSYS ver. 14 software (Ansys Inc., USA) and force orthodontic appliance measurement (The Richmond Orthodontics Stress and Tension Gauge, Ormco, USA). The magnitude of orthodontic force applied was 10, 20 and $30 \mathrm{grF}$. Under general anesthesia induced by intraperitoneal injection of $10 \mathrm{mg} / \mathrm{kgWB}$ ketamine $\mathrm{HCl}$ (Anesject, Danpac Pharma, Indonesia), the upper incisors were prepared with metal strips (Biodinamica Quilm e - Farm. Ltda, Brazil), then the orthodontic appliances were perpendicularly bonded to the tooth axis with glass ionomer cement Fuji IX (GC, Japan), and then smeared with vaseline (Figure 1). The duration of this orthodontic appliances application was performed for seven days. After that, all experimental animals were euthanized using ether anesthesia and the distance between the upper incisors was measured using a digital caliper (SH, China).

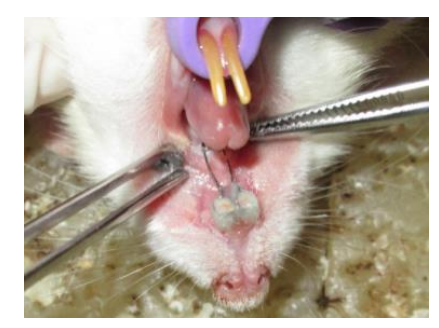

Figure 1. Orthodontic appliances in experimental animals. (1) Orthodontic appliances bonded both on upper incisor (2). Fixed with glass ionomer cement.

\section{Histological preparations}

The maxillary specimens were fixed in 10\% formalin for 24 hours. The upper incisor regions were cut with a diamond bur disk (Hager \& Maisinger, Germany). These specimens were decalcified in 14\% EDTA solution ( $\mathrm{pH} 7.4$ ) for 30 days at $4^{\circ} \mathrm{C}$. They were then exposed to histological procedures and cut using a microtome in serial five $\mu \mathrm{m}$ (HE staining) and three $\mu \mathrm{m}$ (IHC procedure) longitudinal sections. 
IHC staining was performed used an Antibody MMP 9 (sc-6840, SantaCruz Bio Technology, Inc., USA) and IHC kit (Starr Trek Universal HRP Detection System, Biocare Medical, USA). Determination of MMP nine expression was performed using AxioVision Software Rel v 4.8.1. Quantification on the number of fibroblasts was performed using Olympus microscope BX-51 (New York Microscope Company Inc., USA).

\section{Statistical Analysis}

MMP nine expression and the number of fibroblasts on both stress and tension side among each group were analyzed using an independent t-test. To observe the correlation between MMP 9 expression and the number of fibroblasts, data was subjected to Spearman correlation test and followed by regression analysis with SPSS 20.0 software.

\section{RESULTS AND DISCUSSION}

\section{Measurement of distance between upper incisors}

The purpose of this measurement was to determine the distance between the upper incisors due to use of orthodontic different forces for 7 days in normal and diabetic rats. Figure 2 shows that the distance between the upper incisors decreased in line with the magnitude of orthodontic forces. The t-test analysis showed no statistically significant differences between K3 and K6 ( $p=0.32)$.

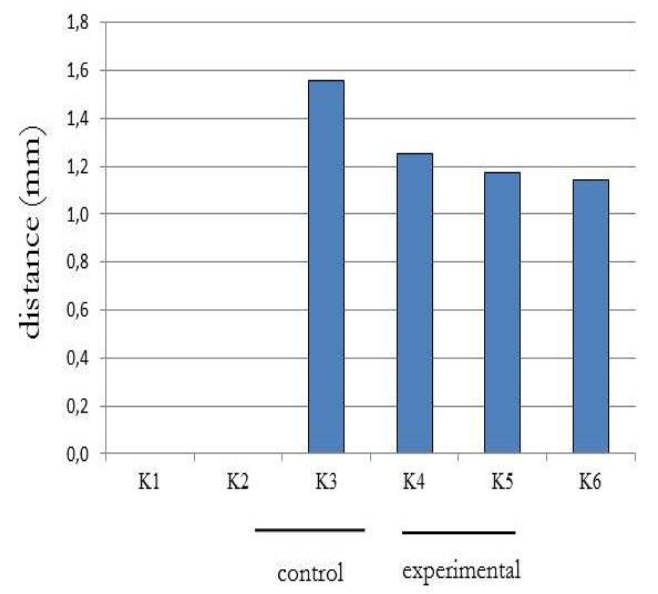

Figure 2. A chart of the distance between upper incisor averages.

\section{Expression of MMP 9 and Number of Fibroblasts}

Figures 3 and 4 present the expression of MMP 9 and the number of fibroblasts in the stress and tension side. Figure 5A shows the expression of MMP 9 in diabetic rats was increased along with the increase of orthodontic force, both in the pressure and tension side. Figure $5 \mathrm{~B}$ showed that the average number of fibroblast cells in diabetic rats decreased as a large magnitude of orthodontic force, both in the pressure and tension side.
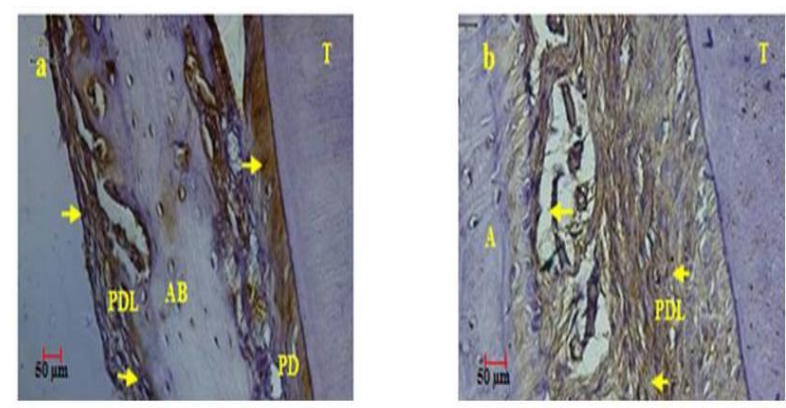

Figure 3. Immunohistochemical image of MMP nine expressions. Yellow darts show expression of MMP nine in the cell and matrix, a. Pressure side, $\mathrm{b}$. Tension side, AB: alveolar bone, T: teeth, PDL: periodontal ligament.
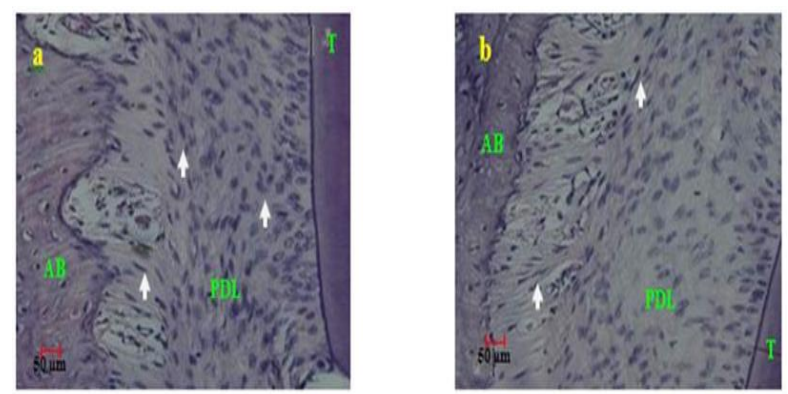

Figure 4. Histological images of fibroblast cells. White arrows show fibroblast in the periodontal ligament, a. Pressure side, b. tension is side. AB: alveolar bone, $\mathrm{T}$ : teeth, PDL: periodontal ligament

The results of t-test analysis of MMP nine expression and the number of fibroblasts showed statistically significant difference in all groups both in the stress and tension side $(p=0.00)$.

Table 1 shows that there is a strong negative relationship between MMP 9 expression and number of fibroblasts in diabetic rats, in the pressure side $(\mathrm{r}=-0.768)$, and in the tension side $(\mathrm{r}=-0.910)$. The results of regression analysis (Table 1) show that in diabetic rats, the 
expression of MMP 9 affects the number of fibroblasts. Based on the coefficient of determination, expression of MMP nine affects

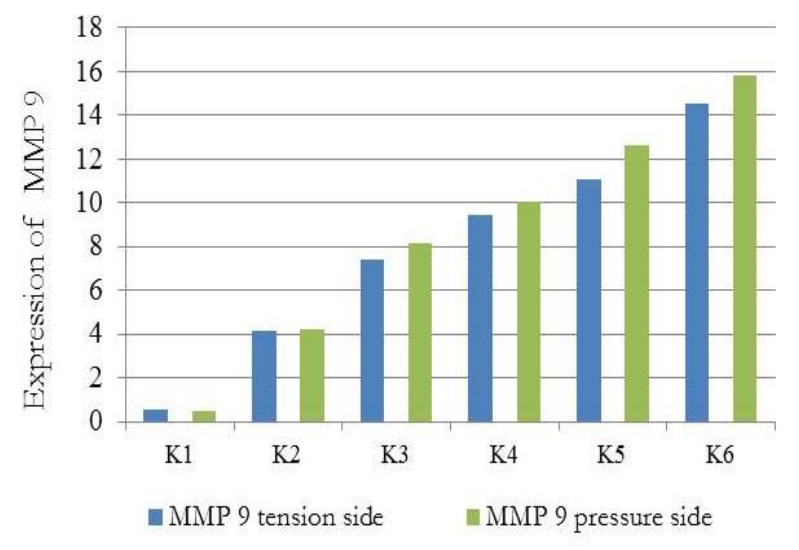

the number of fibroblasts as much as $59 \%$ in pressure side, and $82.9 \%$ in the tension side, and the rest of that was influenced by other factors.

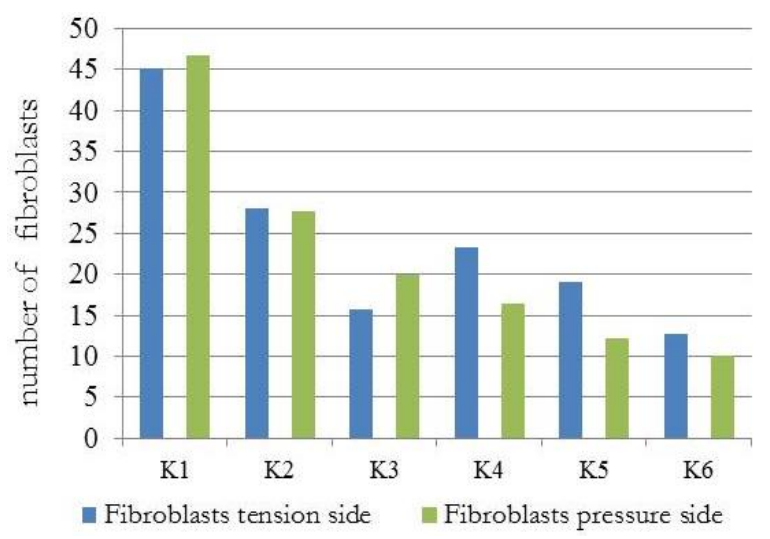

Figure 5. A. Histogram status, expression of MMP 9, shows an increase in line with the development of diabetes and a large magnitude of orthodontic forces; B. Histogram status, a number of fibroblasts decreased with the development of diabetes and a large magnitude of orthodontic forces.

Table 1. Correlation and regression analysis of MMP 9 expression over the amount of fibroblasts on diabetes conditions on the pressure and tension side

\begin{tabular}{|lcc|}
\hline & Pressure side & Tension side \\
\hline $\mathrm{r}$ & -0.768 & -0.910 \\
$\mathrm{R}^{2}$ & 0,590 & 0,829 \\
Coefficient Determination & $59 \%$ & $82,9 \%$ \\
$\mathrm{p}$ Value & $0,000^{*}$ & $0,000^{*}$ \\
& & \\
\hline
\end{tabular}

Orthodontic tooth movement is achieved by the application of orthodontic appliances on teeth that are characterized by remodeling changes in the teeth and periodontal tissues [2]. In this research, orthodontic applances with different force was applied to the teeth for 7 days to produce properly movement of the maxillary incisor. In the orthodontic tooth movement, an initial compression of the periodontal ligament occur from day 0 to 1 . A lag phase with no tooth movement was noted thereafter from day 1 to 5 . That is the period where necrotic tissue accumulated in the compressed area is elimi-nated. Finally, orthodontic tooth movement occurs from day 5 to 10 . But in day 7 achieved an optimum orthodontic toth movement [14]. So, from his statement we decided to designed 7 days experiment. Different orthodontic force which given on the condition of diabetes for seven days, resulted the distance between upper incisors which tend to get smaller as the large magnitude of orthodontic force applied and there was no statistically significant difference $(\mathrm{p}=$ .32). It showed that the magnitude of given orthodontic force $(10,20$ and $30 \mathrm{grF})$ was not directly proportional to the large of distance between upper incisor in the diabetic condition.

The correlation between magnitude of orthodontic force and rate of tooth movement during active treatment is now considered to be a practical tool in identifying optimal forces on an individual basis. An optimal orthodontic force moves teeth efficiently into their desired position, without causing discomfort or tissue damage to the patient, whereas light forces are preferable, because of their ability to evoke frontal resorption of bone. When the force was increased above optimum, the rate of tooth 
movement was decreased and finally approached zero within a week [15]. One of the long-term manifestations of diabetes is periodontitis [16], which can cause great loss of periodontal bone, thus increasing the risk of tooth loss [17]. This is consistent with the statement of Ryan, et al. (1999), that diabetes can improve periodontal tissue damage [7]. Meanwhile, according to Graves, et al. (2006), diabetes causes alveolar bone loss by damaging cycle of bone formation that occurs after the process of bone resorption [18]. The orthodontic force which is given to the rat diabetic models may produce undermining resorption at the pressure side, which caused the decrease of tooth movement.

The results of this study showed that the average expression of MMP 9, which was further increased in diabetic conditions, both on the pressure and tension side along with increase of magnitude force applied. These results are consistent with previous research, that there is increasing of MMP expression during orthodontic tooth movement on both the pressure and tension side [6, 19-21]. Maxwell, et al. (2001) stated that the condition of diabetes is often associated with the presence of infla-mmation, the formation of ROS and increasing of MMP 9 [22]. According to Rajagopalan, et al. (1996), MMP 9 can be activ-ated by ROS through posttranslational modifi-cation [23]. In perio-dontal tissue inflammation, the number of cells that express MMP were increased compared with in healthy tissue [24-26]. Activity of MMPs is regulated at multiple levels, including transcription, activation and inhibition. The most of MMPs are not constitutively expressed by many cells, but its expression is induced by exogenous signals, for example, cytokines (TNF- $\alpha$, IL-1), growth factors (EGF, $\beta F G F$, and PDGF) or changes in matrix cells and contacts between cells [27-28]. Expressions of several MMPs (MMP 1, MMP 3, MMP 7, MMP 9, MMP 10, MMP 12, MMP 13 and MMP 19) were induced at transcriptional level [28].

The results of quantification (Fig. 5 B) showed that the number of fibroblast cells in the diabetic condition decreased as the magnitude of orthodontic force. According Melsen (1999), orthodontic force causes periodontal ligament elongated in the tension side, whereas retracted at the pressure side [29]. Spearman correlation analysis (Table 1) showed that there is a very strong negative correlation between the expression of MMP 9 with the number of fibroblasts in both the ressure and tension side. Whereas the regression analysis showed that MMP 9 affects the number of fibroblasts in both the pressure and tension side.

In diabetes condition, AGE was accumulated in periodontal tissues, which can cause changes in the cells and ECM components. The productions of collagen by fibroblasts in diabetes are particularly vulnerable to rapidly degraded by MMP, which significantly increases in diabetes condition [7]. In diabetics, there is a risk affected periodontal disease, two to five times higher than normal, but will be reduced in a controlled hyperglycemia.

Fibroblast function becomes impaired due to elevated levels of glucose and reduced availability of collagen. Reduced function of fibroblasts and collagen can alter the availability of healing reaction in diabetic patients [30]. This is supported by Koulouri, et al. (1999) which states that there are high levels of fibroblast apoptosis in diabetic patients with periodontitis [31]. Diabetes is associated with the production of pro-apoptotic factors, such as the formation of AGEs, TNF and ROS. AGEs can affect the connective tissue and bone by increasing apoptosis of matrix-producing cells, so the number of cells that producing matrix will be reduced. TNF can induce apoptosis by triggering the occurrence of early apoptosis and stimulates the expression of pro-apoptotic genes [32-33]. ROS is strong inducer of apoptosis [34].

According to Chapple and Matthews (2000), the effects of ROS in periodontal tissues and its components cause periodontal tissue damage through degradation the basic 6 substances, directly or indirectly collagenolisis, or by proteases oxidation [35]. Fibroblasts in perio-dontal ligament respond to mechanical stress by producing inflammatory mediators such as prostaglandins and MMP that stimulates ECM degradation [36]. On the pressure side, the compression of periodontal ligament causes ligament fibers sagging, and fiber degradation appears to be increasing [37]. Periodontal ligament remodeling requires regulation of MMPs and TIMPs [21], and the expressions of TIMP 1 on the tension side were increased in osteoblasts during bone formation [38]. 


\section{CONCLUSIONS}

From the study, it can be concluded that expression of MMP 9 in diabetic disease tends to increase as large magnitude of orthodontic forces is applied either on the pressure or tension side. However, the number of fibroblasts on the tension side has a tendency to decrease compared to the pressure side, and there is a strong negative correlation between the expression of MMP 9 with the number of fibroblasts in rat diabetic models, along with the magnitude of orthodontic forces.

\section{ACKNOWLEDGMENT}

We would like to send our gratitude to DR. Eng. Moch. Agus. Choiron, S.T. M.T., Prof. DR. dr. M. Hidayat, Sp.OT., Abuhari, Wahyu Muji Iswanto, Ferrida, S.P., Surya Kurnia, A.Md., and Sri Wahyuni, A.Md., for their valuable help in conducting this study.

\section{REFERENCES}

1. Dolce C, Malone JS, Wheeler TT. Current concepts in the biology of orthodontic tooth movement. Seminars in orthodontics 2002; 8: 1:6-12.

2. Krishnan V, Davidovitch Z. Cellular, molecular, and tissue level reactions to orthodontic force. Am J Orthod Dentofacial Orthop 2006; 129: 1-32

3. Wise GE, King GJ (2008) Mechanisms of tooth eruption and orthodontic tooth movement. J Dent Res. 8: 87:414-434.

4. Nagase H, Visse R, Murphy G (2006) Structure and function of matrix metalloproteinases and TIMPs : review. Cardiovascular Research. 69: 562- 573.

5. Bode W, Maskos K (2003) Structural basis of the matrix metalloproteinases and their physiological inhibitors, the tissue inhibitors of metalloproteinases. Biol Chem. 384: 863-872.

6. Bildt MM, Bloemen M, Kuijpers-Jagtman AM, Von den Hoff JW (2009) Matrix metalloproteinases and tissue inhibitors of metalloproteinases in gingival crevicular fluid during orthodontic tooth movement. European Journal of Orthodontics. 31: 529-535.

7. Ryan M, Ramamurthy N, Sorsa T, Golub L (1999) MMP-mediated events in diabetes. Ann NY Acad Sci. 878: 311-334.

8. Graves DT, Liu R., Oates TW (2007) Diabetesenhanced inflammation and apoptosis impact on periodontal pathosis. Periodontology 2000. 45: 128-137.

9. Verna C, Dalstra M, Melsen B (2000) The rate and the type of orthodontic tooth movement is influenced by bone turnover in a rat model. Eur J Orthod. 22: 343-352.

10. Li X, Zhang L, Wang N, Feng X, Bi L (2010) Periodontal ligament remodeling and alveolar bone resorption during orthodontic tooth movement in rats with diabetes. Diabetes Technol Ther. 12: 65-73.

11. Nurdiana, Permatasari N, Setyawati, Ali M (1998) Effect of streptozotocin as a diabetogenik agent on wistar rat with intraperitoneal and intravenous inductions. Majalah Kedokteran Unibraw. 14: 6673.

12. Kilic N, Oktay H, Ersoz M (2010) Effects of Force Magnitude on Tooth Movement : An Experimental Study in Rabbits. European Journal of Orthodontics. 32: 154-158.

13. Mirzakouchaki B, Firoozi F, Shahrbar S (2011) Effect of Psychological Stress on Orthodontic Tooth Movement in Rats. Med Oral Patol Oral Cir Bucal. 16: 85-91.

14. Vakani AK. 2003. Effect of Nitric Oxide (NO) on Orthodontic Tooth Movement in Rats. Thesis. University of Florida.

15. Krishnan V and Davidovitch Z. 2006. Cellular, molecular, and tissue reactions to orthodontic force. Am J Orthod Dentofacial Orthop. 129: 1 32.

16. Du X, Matsumura T, Edelstein D, Rossetti L, Zsengeller Z, Szabo C, et al. Inhibition of GAPDH activity by poly (ADP-ribose) polymerase activates three major pathways of hyperglycemic damage in endothelial cells. J Clin Invest 2003; 112: 1049-1057.

17. Nishimura F, Takahashi K, Kurihara M, Takashiba S, Murayama Y. Periodontal disease as a complication of diabetes mellitus. Ann Periodontol 1998; 3: 20-29.

18. Graves DT, Liu R, Alikhani M, Al-Mashat H, Trackman PC. Diabetes-enhanced Inflammation and Apoptosis-Impact on Periodontal Pathology. J Dent Res 2006; 85: 15-21.

19. Apajalahti S, Sorsa T, Railavo S, Ingman T. The in Vivo Levels of Matrix Metalloproteinase-1 and -8 in Gingival Crevicular Fluid during Initial Orthodontic Tooth Movement. J Dent Res 2003; 82: 1018-1022

20. Takahashi I, Nishimura M, Onodera K, Bae JW, Mitani H, Okazaki M, et al. Expression of MMP8 and MMP-13 Genes in the Periodontal Ligament during Tooth Movement in Rats. Journal of Dental Research 2003; 82: 646-651.

21. Takahashi I, Nishimura M, Onodera K, Bae JW, Mitani H, Okazaki M, et al. (2003) Expression of 
MMP-8 and MMP-13 Genes in the Periodontal Ligament during Tooth Movement in Rats. Journal of Dental Research. 82: 646-651.

22. Maxwell P, Timms P, Chandran S, Gordon D (2001) Peripheral blood alterations of TIMP-1, MMP-2, and MMP-9 in patients with type 1 diabetes. Diabet Med. 18: 777-780.

23. Rajagopalan S, Meng XP, Ramasamy S, Harrison DG, Galis ZS (1996) Reactive oxygen species produced by macrophage-derived foam cells regulate the activity of vascular matrix metalloproteinases in vitro. Implications for atherosclerotic plaque stability. J Clin Invest. 98: 2572-2579.

24. Birkedal-Hansen $\mathrm{H}$, Moore WG, Bodden MK, Windsor LJ, Birkedal-Hansen B, DeCarlo A, et al. (1993) Matrix metalloproteinases: a review. Crit Rev Oral Biol Med. 4: 197-250.

25. Tonetti MS, Freiburghaus K, Lang NP, Bickel M (1993) Detection of interleukin-8 and matrix metallo-proteinases transcripts in healthy and diseased gingival biopsies by RNA/PCR. J Periodont Res. 28: 511-513.

26. Tervahartiala T, Pirila E, Ceponis A, Maisi P, Salo T, Tuter G, et al. (2000) The in vivo expression of collagenolytic matrix metalloproteinases (MMP-2, -8, -13, and -14) and matrilysin (MMP7 ) in adult and localized juvenile periodontitis. J Dent Res. 79: 1969-77.

27. Varun BR, Bindu J, Nair STT, Anna PJ (2012) Matrix metalloproteinases and their role in oral diseases: a review. Oral \& Maxillofacial Pathology Journal. 3: 976-1225.

28. Amălinei C, Irina-Draga C, Raluca AB (2007) Biology of metalloproteinases. Romanian Journal of Morphology and Embryology. 48: 323-334.

29. Melsen B (1999) Biological Reaction of Alveolar Bone to Orthodontic Tooth Movement. Angle Orthodontist. 69: 151-158.

30. Ciprian AD, Maria I, Maria M, Raluca CD, Iulia V. The relationship between periodontal disease and diabetes mellitus. Rom J Diabetes Nutr Metab Dis 2012; 19: 181-188.

31. Koulouri O, Lapping D, Radvar M, Kinane D (1999) Cell division, synthetic capacity and apoptosis in periodontal lesions analyzed by in situ hybridization and immunohistochemistry. J Clin Periodontol. 26: 552-559.

32. Alikhani M, Alikhani Z, Graves D (2005) FOXO1 functions as a master switch that regulates gene expression necessary for TNF-induced fibroblast apoptosis. J Biol Chem. 280: 12096-12102.

33. Thorburn A (2004) Death receptor-induced cell killing. Cell Signal. 16: 139-144.

34. Mates J, Sanchez F (2000) Role of reactive oxygen species in apoptosis: implications for cancer therapy. Int J Biochem Cell Biol. 32: $157-$ 170.

35. Chapple ILC, Matthews JB (2007) The role of reactive oxygen and antioxidnt species in periodontal tissue destruction. Periodontology 2000. 43: 160-232.

36. Howard PS, Kucich U, Taliwal R, Korostoff JM (1998) Mechanical forces alter extracellular matrix synthesis by human periodontal ligament fibroblasts. Journal of Periodontal Research. 33: 500-508.

37. Von BM, Maltha JC, Von den Hoff JW, Kuijpers-Jagtman AM (2004) Focal hyalinization during experimental tooth movement in beagle dogs. American Journal of Orthodontics and Dentofacial Orthopedics. 125: 615-623.

38. Bord S, Horner A, Beeton CA, Hembry RM, Compston JE (1999) Tissue inhibitor of matrix metalloproteinase-1 (TIMP-1) distribution in normal and pathological human bone. Bone. 24: $229-235$. 